\title{
Desempenho de Novilhos Mestiços na Fase de Crescimento Suplementados Durante a Época Seca ${ }^{1}$
}

\author{
Paulo Gomes Júnior ${ }^{2}$, Mário Fonseca Paulino ${ }^{3,4}$, Edenio Detmann ${ }^{5}$, Sebastião de Campos \\ Valadares Filho ${ }^{3,4}$, Joanis Tilemahos Zervoudakis ${ }^{6,4}$, Rogério de Paula Lana ${ }^{3,4}$
}

\begin{abstract}
RESUMO - Objetivou-se avaliar o desempenho de novilhos em recria recebendo, durante o período da seca, suplementos constituídos por diferentes fontes protéicas. Os tratamentos empregados foram: sal mineral (MM) e suplementos constituídos pelas fontes protéicas farelo de soja (FS), farelo de algodão (FA), farelo de glúten de milho (FG) e farelo de trigo (FT). Os suplementos foram fornecidos ad libitum, empregando-se uréia e cloreto de sódio como controladores de consumo, ajustados para permitir a ingestão de $1 \mathrm{~kg}$ suplemento/dia. O nível médio de uréia empregado foi de 10\%, com exceção do FT (8\%), o qual parece agir como adjuvante sobre o controle de ingestão. Foram utilizados 35 novilhos mestiços, castrados, com peso médio inicial de 248 kg, distribuídos entre tratamentos e alocados em cinco piquetes ( $8 \mathrm{ha}$ ) de Brachiaria decumbens. O consumo médio de suplementos foi de 0,$046 ; 1,48 ; 1,49 ; 1,50$; e 1,48 kg/animal/dia para os tratamentos MM, FS, FA, FG e FT, respectivamente. Os valores superiores a $1 \mathrm{~kg} /$ dia foram justificados em virtude da elevação de peso dos animais. O ganho médio diário para MM foi de $0,09 \mathrm{~kg} / \mathrm{dia}$, sendo inferior aos tratamentos com suplementação, os quais não diferiram entre si, apresentando média de $0,47 \mathrm{~kg} / \mathrm{dia}$.
\end{abstract}

Palavras-chave: bovinos de corte, suplementação, uréia

\section{Performance of Growing Crossbred Steers Supplemented During the Dry Season}

\footnotetext{
ABSTRACT - The objective of this study was to evaluate the performance of growing steers, during the dry season, fed supplements with different protein sources. The treatments were constituted of: mineral mixture (control) (MM), and supplements including the protein sources soybean meal (SBM), cottonseed meal (CM), corn gluten meal, (CGM) and wheat bran (WB). The supplements were supplied ad libitum, by using urea end sodium chloride as intake controller, adjusted at the level that allow to intake $1 \mathrm{~kg}$ supplement/day. The average urea level was 10\%, except for WB (8\%), which seems also to act as ingestion controller. Thirty five crossbreed steers with $248 \mathrm{~kg}$ of live weight, grazing five Brachiaria decumbens paddocks ( 8 ha), were used. The average intakes of supplements were $0.046,1.48,1.49,1.50$ and $1.48 \mathrm{~kg} /$ animal/day for the treatments MM, SBM, CM, CGM and WB, respectively. The values higher than $1 \mathrm{~kg} /$ day were justified by elevation of weight of the animals. The average daily gain for MM was $0.09 \mathrm{~kg} /$ day, being lower than the supplement treatments, which did not differ to each other, presenting average daily gain of $0.47 \mathrm{~kg} /$ day.

Key Words: beef cattle, supplementation, urea

\section{Introdução}

A fase de recria, segundo Villares (1984), é a que mais contribui para reduzir a eficiência do processo produtivo de criação de bovinos nos trópicos, uma vez que reúne o maior contingente populacional, com cerca de $48,2 \%$ dos bovinos, retendo estes animais por longo tempo, entre 12 e 36 meses, abrangendo 58,3\% do ciclo de produção.

Uma grande contribuição para este longo ciclo da recria é a sazonalidade das pastagens. No Brasil, a

estação de monta é mais comum no período de janeiro a março, com nascimento de outubro a dezembro, períodos que apresentam maior disponibilidade e qualidade das forrageiras. No entanto, os bezerros irão desmamar de maio a julho, período em que a maioria das pastagens tem quantidade e qualidade reduzidas, sendo justamente neste período que se inicia a recria. Segundo Berg \& Butterfield (1979), após o nascimento, por intermédio de manejo e alimentação adequados, os bovinos crescem segundo uma curva sigmoidal, em maior intensidade durante a fase de recria, diminuin-

1 Parte da Dissertação de Mestrado do primeiro autor.

2 Zootecnista, MS, Agroceres Nutrição Animal, Rio Claro-SP.

3 Professor doDepartamento deZootecnia,UniversidadeFederal de Viçosa, Viçosa-MG,36570-000.E.mail:mpaulino@mail.ufv.br; scvfilho@mail.ufv.br

4 Bolsista do CNPq.

5 Zootecnista, Doutor em Nutrição de Ruminantes, DZO/UFV. E.mail: detmann@alunos.ufv.br

6 Zootecnista, MS, Estudante de Doutorado, DZO/UFV.E.mail:joanis@alunos.ufv.br
} 
do à medida que se aproximam da fase adulta. Diante disso, no aproveitamento do potencial de crescimento desta fase em questão, o retorno será a diminuição do ciclo produtivo da pecuária de corte e, conseqüentemente, ampliação do lucro.

As pastagens são a forma mais econômica e prática de alimentação de bovinos. Com isso, torna-se prioridade aumentar a utilização das forragens via otimização do consumo e da disponibilidade de seus nutrientes. Pastagens durante o período seco, em sua maioria, apresentam menos de $7 \%$ de proteína bruta $(\mathrm{PB})$ na matéria seca, havendo, assim, deficiência de proteína degradável no rúmen ( $\mathrm{PDR}$ ) para crescimento microbiano e atividade fermentativa adequados (Van Soest, 1994), causando depressão na digestão da celulose e no consumo, acarretando baixo desempenho animal. Nessas condições, torna-se fundamental a correção da deficiência protéica (Paulino, 1998).

A correção energética pode ocorrer indiretamente com o fornecimento de $\mathrm{PB}$, o que proporcionará aumento na população de microrganismos do rúmen e, conseqüentemente, elevará a digestibilidade da forragem de baixa qualidade e o consumo de matéria seca (MS) e de energia digestível (Reis et al., 1997).

Segundo Leng (1990), a eficiência de utilização da energia metabolizável (EM) da forragem pode ser significativamente melhorada pela suplementação. Ao reduzir as deficiências dos nutrientes, a suplementação garante o crescimento microbiano eficiente, o que pode resultar em eficiente fermentação microbiana para um máximo de extração de carboidratos da forragem, com conseqüente aumento na produção de ácidos graxos voláteis. Além disso, o aumento da síntese microbiana, promovido pela PB fornecida na dieta, eleva a saída de proteína microbiana do rúmen.

A suplementação protéica melhora o desempenho de bovinos consumindo forragens de baixa qualidade, pelo estímulo no consumo voluntário (Vanzant \& Cochran, 1994). Este efeito estimulador da proteína gera um ciclo em que a melhoria na eficiência da síntese microbiana aumenta a digestibilidade da matéria seca, a taxa de diluição e o consumo de forragem e de energia metabolizável, prosseguindo-se o ciclo(Nocek \& Russell, 1988). Nestas condições, tendo-se forragem disponível, mesmo que de baixa qualidade, as condições fornecidas pelo suplemento ao crescimento microbiano possibilitarão maior digestibilidade da forragem.
No enfoque da necessidade de suplementação protéica de ruminantes pastejando forragens de baixa qualidade, seja via proteína verdadeira e, ou, via nitrogênio não-protéico (NNP), tem-se na uréia excelente opção, por ser de baixo custo e potencialmente aproveitável pelos ruminantes. No entanto, se níveis moderados a altos de desempenho são almejados, atenção deve ser dirigida ao fornecimento suplementar de proteína verdadeira, uma vez que constituem a principal fonte de isoácidos, indispensáveis ao adequado metabolismo microbiano.

O objetivo deste trabalho foi avaliar o desempenho produtivo de bovinos mestiços em fase de recria, manejados em pastagem de Brachiaria decumbens, durante o período seco do ano, recebendo suplementos múltiplos compostos por diferentes fontes protéicas.

\section{Material e Métodos}

O experimento foi realizado no período de julho a outubro de 1998 na Fazenda Experimental de Felixlândia-MG (FEFx), de propriedade da Empresa de Pesquisa Agropecuária de Minas Gerais (EPAMIG). As condições climáticas obtidas durante o período experimental são descritas na Tabela 1.

Foram utilizados 35 novilhos mestiços Holandês x Zebu, castrados, com peso e idade médios iniciais de $248 \mathrm{~kg}$ e 10 meses, respectivamente. Os animais foram distribuídos aleatória e balanceadamente entre os tratamentos analisados e alocados em cinco piquetes de Brachiaria decumbens, com aproximadamente 8 hectares, providos de bebedouro e comedouro coberto.

Os tratamentos avaliados constituíram-se da variação na fonte protéica empregada na formulação dos suplementos:

S1. Sal mineral (MM)

S2. Farelo de soja (FS)

S3. Farelo de algodão (FA)

$\mathrm{S} 4$. Farelo de glúten de milho (FG)

S5. Farelo de trigo (FT)

Como estratégia de regulação de consumo, empregaram-se níveis mais elevados de uréia/sulfato de amônia, conforme preconizações de Paulino et al. (1983, 1996a). Para tal, conduziu-se, anteriormente ao início do experimento, um período de avaliação do consumo suplementar diário, visando-se estabelecer o nível necessário para permitir ingestão média de $1 \mathrm{~kg} / \mathrm{animal} /$ dia. Esta meta foi alcançada com o emprego de $10 \%$ da mistura uréia/sulfato de amônia, com exceção de FT 
(8\%), indicando possível existência de efeito adjuvante sobre o consumo de suplemento, aliado a altos níveis desta fonte alimentar. A composição média dos ingredientes utilizados na formulação dos suplementos, expressa na matéria natural, consta da Tabela 2.

Durante o período experimental, os comedouros foram mantidos medianamente cheios, buscando-se

Tabela 1 - Médias de temperaturas, máxima e mínima, umidade relativa do ar (URA) e precipitação total (PT), durante o período experimental

Table 1 - High and low average temperatures, relative air moisture (RMA) and total rainfall (TR) in the experimental period

Mês ${ }^{1}$ Temperatura média $\left({ }^{\circ} \mathrm{C}\right)$

Month ${ }^{1}$ Average temperature $\left({ }^{\circ} \mathrm{C}\right)$

\begin{tabular}{lcccc}
\cline { 2 - 3 } & $\begin{array}{c}\text { Máxima } \\
\text { High }\end{array}$ & $\begin{array}{c}\text { Mínima } \\
\text { Low }\end{array}$ & $\begin{array}{c}\text { URA (\%) } \\
P T(\mathrm{~mm})\end{array}$ & $\begin{array}{c}\text { RMA (\%) } \\
\text { TR }(\mathrm{mm})\end{array}$ \\
\hline $\begin{array}{l}\text { Julho } \\
\text { July }\end{array}$ & 28,9 & 10,0 & 60,7 & 0,0 \\
$\begin{array}{l}\text { Agosto } \\
\begin{array}{l}\text { August } \\
\text { Setembro }\end{array}\end{array}$ & 31,0 & 14,3 & 54,6 & 18,3 \\
$\begin{array}{l}\text { September } \\
\begin{array}{l}\text { Outubro } \\
\text { October }^{2}\end{array}\end{array}$ & 31,2 & 16,3 & 49,6 & 2,0 \\
\hline
\end{tabular}

${ }^{1}$ Fonte: estação metereológica FEFx.

2 Dados coletados de $1^{\circ}$ a 15 de outubro.

1 Source: meteorological station FEFX.

2 Data collected from October $1^{\text {st }}$ to $15^{\text {th }}$. evitar restrição ao consumo de suplemento. Da mesma forma, procurou-se manter a mesma disponibilidade de mistura mineral para o tratamento controle. No momento do fornecimento de suplemento ou mistura mineral, estes eram pesados, para que posteriormente fosse estimado o consumo médio diário.

A cada 28 dias, os animais foram pesados e rotacionados entre piquetes, com o objetivo de eliminar possíveis interferências relacionadas a esta fonte sobre o desempenho. Concomitantemente a este procedimento, efetuou-se a quantificação das sobras de suplementos.

A avaliação da disponibilidade total de matéria seca na pastagem foi realizada por intermédio de corte, ao nível do solo, dentro de cada piquete, de dez áreas, delimitadas por um quadrado metálico de $1 \times 1 \mathrm{~m}$. A qualidade da dieta ingerida pelos animais foi estimada por intermédio de simulação manual de pastejo, conforme técnicas descritas por Johnson (1978). As avaliações quantitativa e qualitativa foram realizadas ao início e final do período experimental, sendo os valores expressos com base na média entre as coletas.

As amostras de suplementos e pastejo simulado foram analisadas quanto aos teores de matéria seca (MS), proteína bruta $(\mathrm{PB})$, cálcio $(\mathrm{Ca})$ e fósforo (P), segundo técnicas descritas por Silva (1990).

Tabela 2 - Composição dos suplementos, com base na matéria natural

Table 2 - Composition of the supplements, as fed basis

\begin{tabular}{|c|c|c|c|c|c|}
\hline \multirow[t]{2}{*}{$\begin{array}{l}\text { Alimentos (\%) } \\
\text { Feeds (\%) }\end{array}$} & \multicolumn{5}{|c|}{$\begin{array}{l}\text { Suplementos } \\
\text { Supplements }\end{array}$} \\
\hline & $\mathrm{MM}$ & FS & FA & $\mathrm{FG}$ & FT \\
\hline $\begin{array}{l}\text { Sal mineral } \\
\text { Mineral salt }\end{array}$ & 100,0 & 6,0 & 6,0 & 6,0 & 6,0 \\
\hline $\begin{array}{l}\text { Sal comum }(\mathrm{NaCl}) \\
\text { Salt }\end{array}$ & - & 4,0 & 4,0 & 4,0 & 4,0 \\
\hline $\begin{array}{l}\text { Uréia/Sulf.amônia }(9: 1) \\
\text { Urea/Ammonium sulfate }(9: 1)\end{array}$ & - & 10,0 & 10,0 & 10,0 & 8,0 \\
\hline $\begin{array}{l}\text { Farelo de soja } \\
\text { Soybean meal }\end{array}$ & - & 15,0 & - & - & - \\
\hline $\begin{array}{l}\text { Farelo de algodão } \\
\text { Cottonseed meal }\end{array}$ & - & - & 30,0 & - & - \\
\hline $\begin{array}{l}\text { Farelo de glúten de milho } \\
\text { Corn gluten meal }\end{array}$ & - & - & - & 10,0 & - \\
\hline $\begin{array}{l}\text { Farelo de trigo } \\
\text { Wheat bran }\end{array}$ & - & 65,0 & 50,0 & 70,0 & 82,0 \\
\hline
\end{tabular}


Para obtenção dos níveis de proteína degradável no rúmen dos suplementos, empregaram-se os valores relatados NRC (1996). Os teores de fibra em detergente neutro (FDN) e resíduo em detergente ácido (RDA) para amostras de pastejo simulado seguiram os métodos de Van Soest et al. (1991). A estimação dos nutrientes digestíveis totais (NDT) para os suplementos baseou-se na equação proposta por Lofgreen (1953): NDT = DIVMS - cinzas $+1,25$ $\mathrm{x} E \mathrm{E}+1,9$, em que DIVMS é digestibilidade in vitro da matéria seca (Tilley \& Terry, 1963) e EE, extrato etéreo. A composição químico-bromatológica de suplementos e amostras de pastejo simulado é apresentada nas Tabelas 3 e 4, respectivamente.

$\mathrm{O}$ experimento foi analisado conforme delineamento inteiramente casualizado, com cinco tratamentos e sete repetições, segundo o modelo:

$$
\mathrm{Yij}=\mathrm{m}+\mathrm{Si}+\mathrm{eij}
$$

em que Yij = valor da variável ganho de peso, referente ao animal $\mathrm{i}$ e ao suplemento $\mathrm{j} ; \mathrm{m}=$ constante geral; $\mathrm{Si}=$ efeito relativo ao suplemento $\mathrm{i}$, sendo $\mathrm{i}=$ $1,2,3,4$ e 5; e eij = erro aleatório, associado a cada observação, pressuposto $\operatorname{NID}\left(0, \sigma^{2}\right)$.

Para comparação entre médias de tratamentos, empregou-se o teste de Newman-Keuls (SNK). Adotou-se $\alpha=0,05$.

\section{Resultados e Discussão}

Os piquetes experimentais apresentaram disponibilidade média de $6.454 \mathrm{~kg}$ de $\mathrm{MS} / \mathrm{ha}$, caracterizada como sendo de baixa qualidade, por apresentar valores elevados de fibra, teores reduzidos de mineriais e proteína e baixa digestibilidade (Tabela 4). Entretanto, a elevada disponibilidade de matéria seca ensejou oportunidade para pastejo seletivo, pressupondo-se, portanto, que a forragem disponível atenderia às exigências de mantença dos animais.

Os consumos voluntários diários médios dos suplementos foram 0,$046 ; 1,48 ; 1,49 ; 1,50$; e 1,48 kg, na matéria natural, para os tratamentos MM, FS, FA, FG e FT, respectivamente. Observa-se que, embora os suplementos tenham sido fornecidos ad libitum, os animais mantiveram um consumo controlado. A utilização de uréia/sulfato de amônia e sal comum como limitadores de consumo, preconizada por Paulino et al. (1983; 1996a), mostrou-se eficiente. Os valores encontrados, acima de $1 \mathrm{~kg}$, refletem o fato de o ajustamento do consumo ter sido feito ao início do experimento; o alto valor observado foi em resposta ao incremento de peso dos animais.

O fornecimento de suplementos, em regime de autocontrole de consumo, para animais na fase de

Tabela 3 - Composição químico-bromatológica da mistura mineral e suplementos, em porcentagem da matéria seca Table 3 - Chemical composition of mineral mixture and supplements, in dry matter basis (\% of dry matter)

\begin{tabular}{|c|c|c|c|c|c|}
\hline & \multicolumn{5}{|c|}{$\begin{array}{c}\text { Suplementos } \\
\text { Supplements }\end{array}$} \\
\hline & $\mathrm{MM}$ & $\mathrm{FS}$ & FA & FG & FT \\
\hline $\mathrm{MS}^{1}$ & 98,00 & 86,49 & 87,25 & 87,33 & 86,49 \\
\hline \multicolumn{6}{|l|}{$D M$} \\
\hline PB & - & 46,09 & 46,92 & 45,80 & 35,94 \\
\hline \multicolumn{6}{|l|}{$C P$} \\
\hline $\mathrm{PDR}^{2}$ & - & 88,02 & 85,36 & 85,02 & 88,56 \\
\hline \multicolumn{6}{|l|}{$R D P$} \\
\hline NDT & - & 72,83 & 66,84 & 72,41 & 70,64 \\
\hline \multicolumn{6}{|l|}{$T D N$} \\
\hline $\mathrm{Ca}$ & 11,30 & 0,84 & 0,80 & 0,77 & 0,78 \\
\hline $\mathrm{P}$ & 8,52 & 1,19 & 1,20 & 1,17 & 1,25 \\
\hline
\end{tabular}


Tabela 4 - Composição químico-bromatológica de amostras de forragem obtidas por simulação manual de pastejo, em porcentagem da matéria seca

Table 4 - Mean chemical composition of forage samples taked by hand plucking sample in dry matter basis

\begin{tabular}{lc}
\hline Item & $\begin{array}{c}\text { Concentração } \\
\text { Content }\end{array}$ \\
\hline $\begin{array}{l}\text { Matéria seca } \\
\text { Dry matter }\end{array}$ & 55,52 \\
$\begin{array}{l}\text { Proteína bruta } \\
\text { Crude protein }\end{array}$ & 3,96 \\
$\begin{array}{l}\text { Fibra em detergente neutro } \\
\text { Neutral detergent fiber }\end{array}$ & 79,02 \\
$\begin{array}{l}\text { Resíduo em detergente ácido } \\
\text { Acid detergent residue }\end{array}$ & 41,66 \\
$\begin{array}{l}\text { Digestibilidade } \\
\text { Digestibility }\end{array}$ & \\
Cálcio & 48,50 \\
$\begin{array}{l}\text { Calcium } \\
\text { Fósforo }\end{array}$ & 0,41 \\
Phosphorus & 0,06 \\
\hline $\begin{array}{l}\text { 1 Digestibilidade in vitro da matéria seca (Tilley \& Terry, 1963). } \\
\text { "In vitro" dry matter digestibility (Tilley \& Terry, 1963). }\end{array}$
\end{tabular}

recria, facilita o manejo e racionaliza a utilização de mão-de-obra na distribuição dos mesmos na pastagem; além disso, evita que o animal crie dependência do suplemento e apresenta aspectos positivos sob o ponto de vista nutricional, pois possibilita melhor sincronização entre energia e proteína e melhor estabilidade em termos de $\mathrm{pH}$ e amônia no ambiente ruminal (Paulino, 2000).

Observa-se, na Tabela 5, que os suplementos atenderam, em média, 25,95 e 27,95\% dos requerimentos de MS e NDT, respectivamente. Quando a forragem contém baixa concentração de um ou mais nutrientes limitantes, tanto para os microrganismos ruminais, como para o animal hospedeiro, o fornecimento de suplemento com alta concentração destes nutrientes gera efeitos associativos benéficos entre forragem e concentrado (Dixon \& Stockdale, 1999). Neste enfoque, ressalta-se que o objetivo não foi atender diretamente às exigências dos bovinos, o que caracterizaria efeito associativo negativo ou substitutivo, mas sim estimular o consumo e a digestão do pasto seco e, dessa maneira, permitir aos animais satisfação de suas exigências (Paulino et al., 1995a). Os suplementos atenderam em totalidade às exigências em proteína bruta, com exceção ao tratamento FT, que supriu 76,92\%, como reflexo do menor nível de uréia/sulfato de amônia empregado. Os altos valores de proteína degradada no rúmen deveram-se, em maior parte, ao elevado nível de uréia empregado nos suplementos e às frações protéicas degradáveis no rúmen das diferentes fontes utilizadas em cada tratamento (Tabela 3). Nota-se que o consumo de MM supriu apenas $24,4 \%$ de $\mathrm{P}$, enquanto os suplementos, próximo de $100 \%$ das exigências.

O desempenho dos animais, em termos de desenvolvimento ponderal, caracterizado pelos pesos vivos inicial e final e ganhos de peso diário médio, é mostrado na Tabela 6 e na Figura 1. Os animais submetidos aos tratamentos com suplementação apresentaram desempenhos semelhantes $(\mathrm{P}>0,05)$ entre si e superiores $(\mathrm{P}<0,05)$ ao dos animais que receberam apenas mistura mineral.

A forragem disponível, caracterizada como de baixa qualidade (Tabela 4), proporcionou nutrientes compatíveis com requerimentos próximos à mantença, o que refletiu no desempenho do grupo de animais que recebiam mistura mineral, ou seja, $0,09 \mathrm{~kg} /$ animal $/$ dia.

Os suplementos fornecidos, ao atenderem níveis adequados de $\mathrm{P}$, proteína bruta e compostos nitrogenados degradáveis no rúmen acima dos níveis preconizados, propiciaram, possivelmente, ambiente ruminal favorável para fermentação da forragem consumida, ensejando liberação de energia para suprir a exigência dos animais para ganhos em torno de $500 \mathrm{~g} /$ dia (Tabela 6).

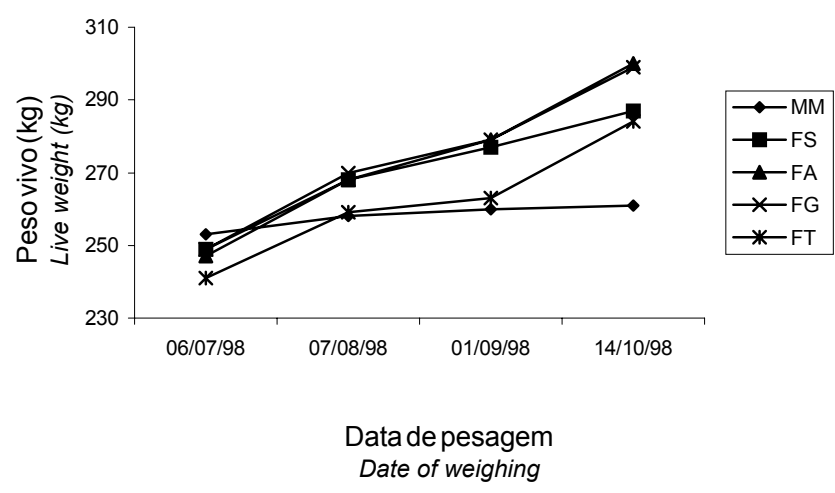

Figura 1 - Desenvolvimento ponderal dos animais, em função dos diferentes suplementos.

Figure 1 - Pondered performance of animals, according to the supplements. 


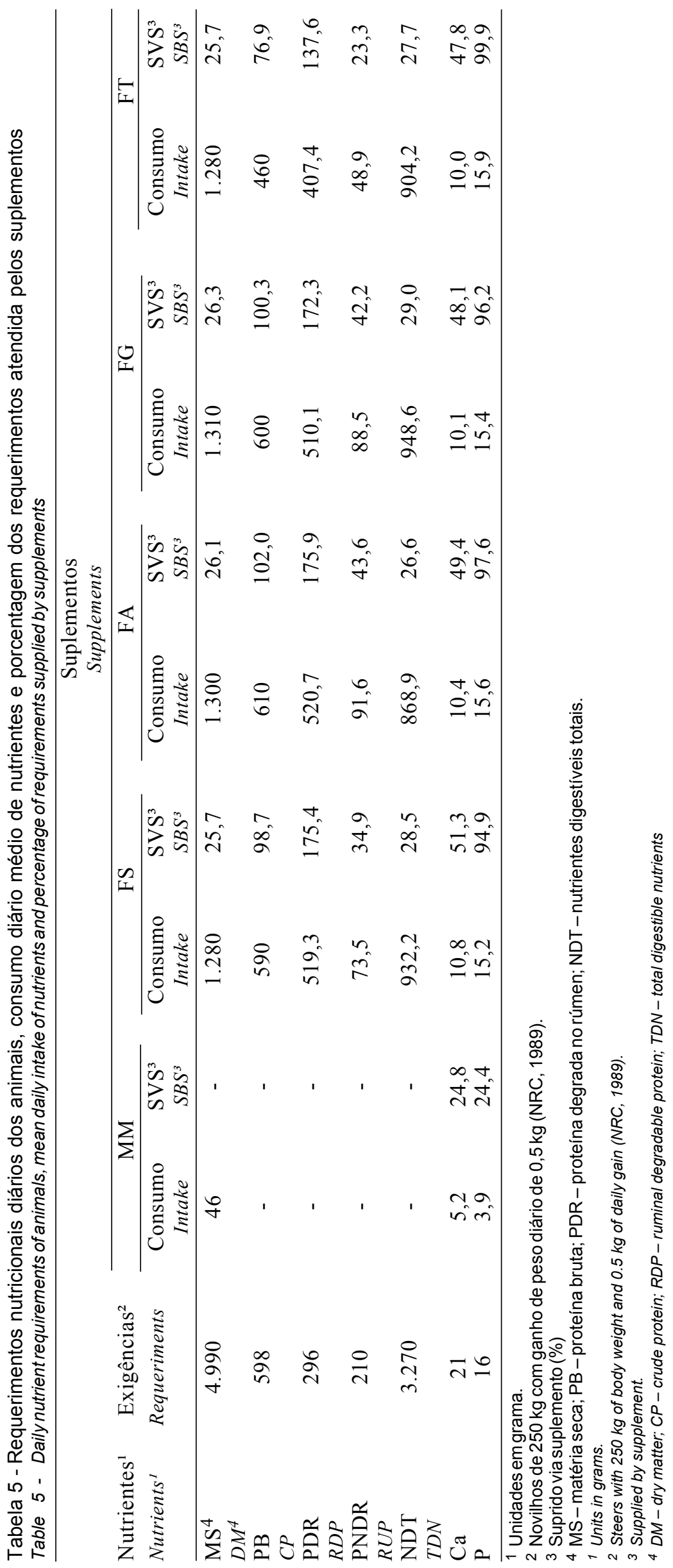


Tabela 6 - Pesos vivos médios, inicial (PVMi) e final (PVMf) e ganho de peso médio diário (GPMD), em $\mathrm{kg}$, para os diferentes suplementos

Table 6 - Initial (ILW) and final (FLW) live weights and average daily gain, in $\mathrm{kg}$, according to the supplements

\begin{tabular}{lccccc}
\hline Item & \multicolumn{5}{c}{$\begin{array}{c}\text { Suplementos } \\
\text { Supplements }\end{array}$} \\
\cline { 2 - 6 } & MM & FS & FA & FG & FT \\
\hline PVMi & 253 & 249 & 247 & 249 & 241 \\
$I L W$ & & 287 & 300 & 299 & 284 \\
PVMf & 261 & & & & \\
$F L W$ & & $0,39^{\mathrm{a}}$ & $0,54^{\mathrm{a}}$ & $0,50^{\mathrm{a}}$ & $0,43^{\mathrm{a}}$ \\
$\mathrm{GPMD}^{1}$ & $0,09^{\mathrm{b}}$ & & & & \\
$A D G^{1}$ & & & &
\end{tabular}

${ }^{1}$ Médias, na linha, seguidas por letras diferentes, são diferentes $(P<0,05)$ pelo teste Newman-Keulls.

${ }^{1}$ Means, in a row, followed by different letters, are different $(P<.05)$ by Newman-Keulls test.

Embora suprindo menor nível de proteína bruta, observou-se desempenho similar entre FT e os demais tratamentos $(\mathrm{P}>0,05)$ (Tabela 6). Ao compararem diferentes fontes de energia na composição de suplementos múltiplos para bovinos em recria, Paulino et al. (1996b) observaram, embora sem significância estatística, melhor desempenho dos animais que recebiam farelo de trigo, o que foi atribuído às características de degradação deste alimento, possibilitando melhor sincronização com a liberação de amônia a partir da uréia e fixação na forma de proteína microbiana. Por outro lado, observa-se que, mesmo fornecendo nível inferior de proteína bruta, o tratamento FT propiciou níveis adequados de proteína degradável no rúmen, o que releva o fato de constituir, em condições de deficiência quantitativa de compostos nitrogenados, como em pastagens tropicais durante a época seca, o primeiro nutriente limitante ao desenvolvimento dos animais, além de, possivelmente, refletir otimização da atividade microbiana ruminal.

Em adição ao comportamento demonstrado pelo tratamento FT, observou-se, embora sem diferença significativa $(\mathrm{P}>0,05)$, leve superioridade no desempenho dos animais submetidos aos tratamentos FA e FG (Tabela 6). Comportamento semelhante foi relatado por Paulino et al. (1992), ao avaliarem as fontes protéicas farelo de algodão, farelo de soja e farinha de carne e ossos. Segundo esses autores, o melhor desempenho propiciado pelo farelo de algodão refle- tiu, possivelmente, características de adequação de degradação que favoreceram o uso da uréia. Este aspecto deve ser priorizado nas fontes naturais de proteína e energia empregadas na formulação de suplementos, tendo em vista os níveis elevados de uréia empregados, quer seja como fonte de compostos nitrogenados ou limitador de consumo (Paulino, 2000). Em outro enfoque, conforme mostrado na Tabela 5, os tratamentos FG e FA, embora suprindo níveis similares aos demais tratamentos em proteína degradável, forneceram níveis levemente superiores de proteína não-degradável no rúmen, o que pode favorecer o desempenho animal, nos casos de supridos os requerimentos em compostos nitrogenados dos microrganismos ruminais (Klopfenstein, 1996).

Considerando-se que animais em recria devem apresentar ganhos de peso moderados, visando proporcionar o desenvolvimento do esqueleto e da musculatura e aproveitar racionalmente o crescimento compensatório, que ocorre com o retorno das boas condições de pastagens na época chuvosa, os suplementos usados proporcionaram resultados favoráveis. Os resultados obtidos nesta pesquisa corroboram os relatos de Paulino et al. (1992; 1995b, c; 1996).

$\mathrm{Na}$ Tabela 7 são apresentados os custos dos suplementos e os ganhos médios diários por animal excedentes ao tratamento controle (MM). Ao se considerarem os ganhos numéricos obtidos com cada tratamento, obteve-se maior retorno com a fonte protéica farelo de algodão, uma vez que apresentou ganho levemente superior aos demais tratamentos, embora sem diferença significativa $(\mathrm{P}>0,05)$. Observou-se que o tratamento constituído pela fonte protéica farelo de soja mostrou o menor desempenho econômico, o que se atribui não somente ao menor desempenho numérico, como também ao seu custo relativamente elevado. Por outro lado, ao considerar-se estritamente o resultado apontado pela análise estatística dos dados, ou seja, assumindo-se média de ganho comum aos tratamentos, uma vez não sendo encontradas diferenças significativas $(\mathrm{P}>0,05)(0,38 \mathrm{~kg} / \mathrm{dia})$, observou-se superioridade econômica ao tratamento FT, o que reflete diretamente o baixo custo deste alimento. Variações no retorno econômico refletem-se diretamente em condições regionais e período do ano em que os alimentos são adquiridos. 
Tabela 7 - Custos de suplementos e ganho médio diário excedente ao tratamento controle (MM), para os diferentes tratamentos

Table 7 - Supplements costs and excess average daily gain to control treatment (MM) for different treatments

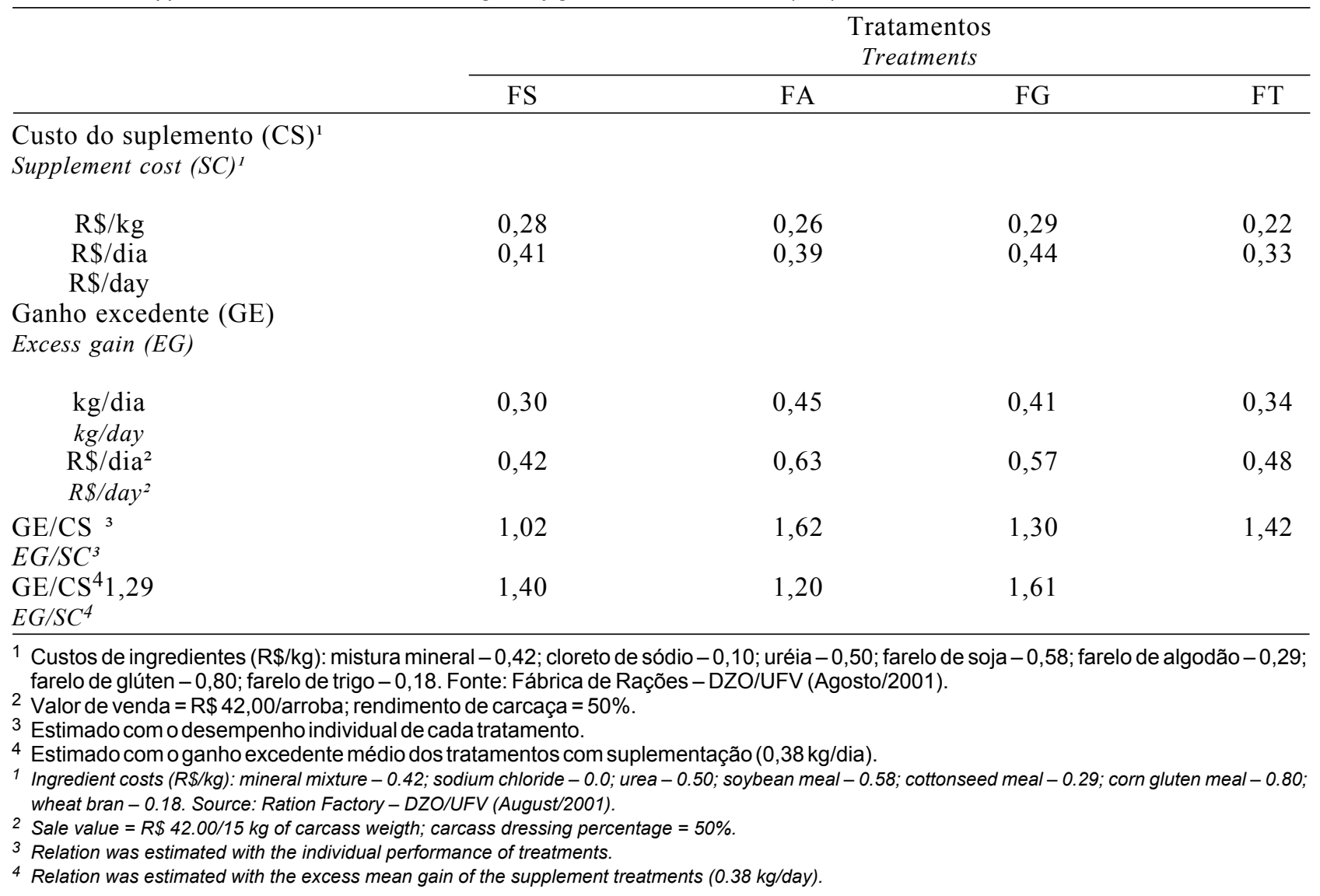

\section{Conclusões}

Os animais submetidos aos tratamentos suplementares apresentaram desempenho semelhante entre si, porém superior ao controle, contendo somente mistura mineral. A suplementação propiciou bom nível de desenvolvimento de bovinos em fase de recria, durante a época seca do ano.

A escolha da fonte de proteína deve ser realizada em função do custo e/ou disponibilidade regional, uma vez não detectadas diferenças entre as fontes analisadas quanto ao desempenho dos animais.

\section{Literatura Citada}

BERG, R.T.; BUTTERFIELD, R.M. Nuevos conceptos sobre desarrollo de ganado vacuno. Zaragoza: Acribia, 1979. 297p.

DIXON, R.M.; STOCKDALE, C.R. Associative effects between forages and grains: consequences for feed utilization. Australian Journal of Agriculture Research, v.50, p.757-73, 1999.

JOHNSON, A.D. Sample preparation and chemical analysis of vegetation In: MANETJE, L.T. (Ed.). Measurement of grassland vegetation and animal production. Aberustwyth: Vommonwcalth Agricultural Burcaux, 1978. p.96-102.

KLOPFENSTEIN, T. Need for escape protein by grazing cattle. Animal Feed Science Technology, v.60, p.191-199, 1996.

LENG, R.A. Factors affecting the utilization of "poor-quality" forages by ruminants particularly under tropical conditions. Nutrition Research Review, v.3, n.3, p.277-303, 1990.

LOFGREEN, G.P. The estimation of total digestible nutrients from digestible organic matter. Journal of Animal Science, v.12, p.359, 1953.

NATIONAL RESEARCH COUNCIL - NRC. Nutrient requirements of dairy cattle. 6.ed. Washington, DC: Academic Press, 1989. 157p.

NATIONAL RESEARCH COUNCIL - NRC. Nutrient requirements of beef cattle. 7.ed. Washington, DC.: Academic Press, 1996. 242p.

NOCEK, J.E.; RUSSELL, J.B. Protein and energy as a integrated system. Relationship of ruminal protein and carbohydrate availability to microbial synthesis and milk production. Journal of Dairy Science, v.71, p.2070-2107, 1988.

PAULINO, M.F. Suplementos múltiplos para recria e engorda de bovinos em pastagens. In: CONGRESSO NACIONAL DOS ESTUDANTES DE ZOOTECNIA, 1998, Viçosa. Anais... Viçosa: Associação Mineira dos Estudantes de Zootecnia, 1998. p.173-188. 
PAULINO, M.F. Suplementação de bovinos em pastejo. Informe Agropecuário, v.21, n.205, p.96-106, 2000.

PAULINO, M.F.; RUAS, J.R.M.; REHFELD, O.A.M. et al. Efeito de diferentes níveis de uréia sobre o desenvolvimento de novilhas zebu. Arquivo Brasileiro de Medicina Veterinária e Zootecnia, v.35, n.2, p.231-245, 1983.

PAULINO, M.F.; ARRUDA, M.L.R.; RUAS, J.R.M. et al. Efeitos de diferentes fontes de proteína sobre o desenvolvimento de novilhas em pastoreio. In: REUNIÃO ANUAL DA SOCIEDADE BRASILEIRA DE ZOOTECNIA, 29., 1992, Lavras. Anais... Lavras: Sociedade Brasileira de Zootecnia, 1992. p.158.

PAULINO, M.F.; RUAS, J.R.M.; ARRUDA, M.L.R. et al. Diferentes fontes de energia em suplementos múltiplos sobre o desenvolvimento de novilhas mestiças em pastagens. In: REUNIÃO ANUAL DA SOCIEDADE BRASILEIRA DE ZOOTECNIA, 32., 1995, Brasília. Anais... Brasília: Sociedade Brasileira de Zootecnia, 1995a. p.252-254.

PAULINO, M.F.; ARRUDA, M.L.R.; RUAS, J.R.M. et al. Efeito do farelo de trigo em substituição ao milho desintegrado com palha e sabugo, em suplementos múltiplos, sobre o desenvolvimento de bezerros nelores em pastoreio. In: REUNIÃO ANUAL DA SOCIEDADE BRASILEIRA DE ZOOTECNIA, 32., 1995, Brasília. Anais... Brasília: Sociedade Brasileira de Zootecnia, 1995b. p.250-252.

PAULINO, M.F.; RUAS, J.R.M.; FURTADO, M.A. et al. Efeito da farinha de carne e ossos e farinha de penas e vísceras, em suplementos múltiplos, sobre o desenvolvimento de bezerras mestiças sob pastejo. In: REUNIÃO ANUAL DA SOCIEDADE BRASILEIRA DE ZOOTECNIA, 32., 1995, Brasília. Anais... Brasília: Sociedade Brasileira de Zootecnia, 1995c. p.255-257.

PAULINO, M.F.; BORGES, L.E.; CARVALHO, P.P. et al. Cloreto de sódio em suplementos múltiplos sobre o desenvolvimento de novilhos mestiços em pastejo, durante a época seca. In: REUNIÃO ANUAL DA SOCIEDADE BRASILEIRA DE ZOOTECNIA, 33., 1996, Fortaleza. Anais... Fortaleza: Sociedade Brasileira de Zootecnia, 1996a. p.19-21.
PAULINO, M.F.; RUAS, J.R.M.; FURTADO, M.A. et al. Fontes de energia em suplementos múltiplos sobre o desenvolvimento de novilhas mestiças em pastagens de capimbrachiaria, durante a época seca. In: REUNIÃO ANUAL DA SOCIEDADE BRASILEIRA DE ZOOTECNIA, 33., 1996, Fortaleza. Anais... Fortaleza: Sociedade Brasileira de Zootecnia, 1996b. p. 16-18.

REIS, R.A.; RODRIGUES, L.R.A.; PEREIRA, J.R.A. A suplementação como estratégia de manejo da pastagem. In: SIMPÓSIO SOBRE MANEJO DE PASTAGEM, 13., 1997, Piracicaba. Anais... Piracicaba: Fundação de Estudos Agrários Luiz de Queiroz, 1997. p.123-150.

TILLEY, J.M.A.; TERRY, R.A. A two-stage technique for the in vitro digestion of forage crops. Journal British Grassland Society, v.18, n.2, p.104-111, 1963.

SILVA,D.J. Análise de alimentos (métodos químicos e biológicos). 2.ed. Viçosa: Universidade Federal de Viçosa, 1990. $156 \mathrm{p}$.

Van SOEST, P.J. Nutritional ecology of the ruminant. 2.ed. Ithaca: Cornell University Press, 1994. 476p.

Van SOEST, P.J.; ROBERTSON, J.B.; LEWIS, B.A. Methods for dietary fiber, and nonstarch polysaccharides in relation to animal nutrition. Journal of Dairy Science, v.74, n.10, p.3583-3597, 1991.

VANZANT, E.S.; COCHRAN, R.C. Performance an forage utilization by beef cattle receiving increasing amont of alfafa hay as a suplement to low-quality, tallgrass-prairie forage. Journal of Animal Science, 73:1059-1067, 1994.

VILLARES, J.B. Zebu e produtividade de bovinos nos trópicos. In: REUNIÃO ANUAL DA SOCIEDADE BRASILEIRA DE ZOOTECNIA, 1984, Belo Horizonte. Anais... Belo Horizonte: Sociedade Brasileira de Zootecnia, 1984. p.76.

Recebido em: 25/05/01

Aceito em: 24/09/01 